\title{
EFFECT OF COOLING ON THE TORQUE OF Tapping Processes in Polymer Composites
}

\author{
Domingo, R.; DE Agustina, B. \& MARIN, M.M.
}

Abstract: The tapping process in polymer composites has been analysed; threaded holes have been formed in reinforced polyamide with glass fibre, PA66-GF30, with a tap of $15^{\circ}$ as taper angle and titanium nitride, TiN, as coating. These tests have been carried out under different environmental temperatures by means of compressed cooling air through vortex tube. The cutting speeds reached values of $15,37.5$ and 60 $\mathrm{m} / \mathrm{min}$ and environmental temperatures values of $-18,2$ and $22{ }^{\circ} \mathrm{C}$. After an experimental data collection and a statistical analysis focussed on an analysis of variance and a response surface to create a second-order regression model, some interesting results are obtained. The lower torque can be found at temperatures close to $3{ }^{\circ} \mathrm{C}$ and at high cutting speeds in the range studied, although the significant factor is the temperature; the cutting speed has a low influence. Therefore, the cooling has been an adequate procedure to reduce the torques.

Key words: Machining, tapping, polymer-matrix composite, polyamide, cooling
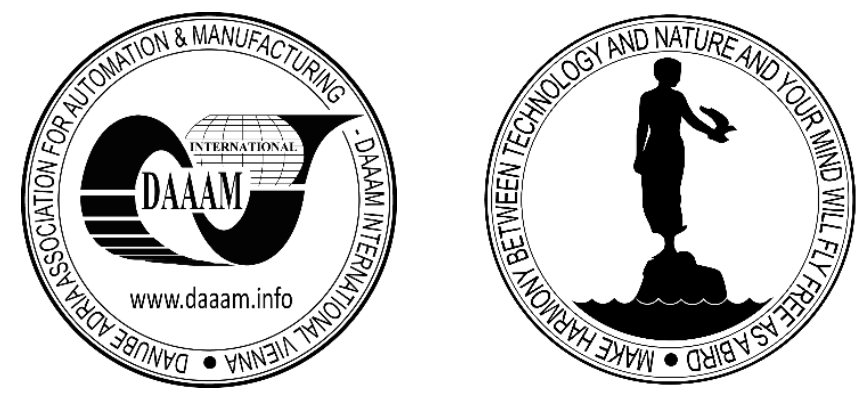

Authors' data: Full Professor Domingo, R[osario]; Associate Professor de Agustina, B [eatriz]; Associate Professor Marin [Marta M.], Universidad Nacional de Educación a Distancia (UNED), Department of Construction and Manufacturing Engineering, Calle Juan del Rosal 12, 28040, Madrid, Spain, rdomingo@ind.uned.es, bdegaustina@ind.uned.es, mmarin@ind.uned.es

This Publication has to be referred as: Domingo, R[osario]; De Agustina, B[eatriz] \& Marin, M[arta M.] (2018). Effect of Cooling on the Torque of Tapping Processes in Polymer Composites, Chapter 22 in DAAAM International Scientific Book 2018, pp.257-264, B. Katalinic (Ed.), Published by DAAAM International, ISBN 978-3902734-19-8, ISSN 1726-9687, Vienna, Austria

DOI: $10.2507 /$ daaam.scibook.2018.22 
Domingo, R.; De Agustina, B. \& Marin, M. M.: Effect of Cooling on the Torque of ...

\section{Introduction}

In the industry, daily many tapping operations are executed as final task in the realisation of holes. These operations with previous drilling tasks are part of assembly processes. The study of tapping is important because of the process complexity where generally high temperatures are generated. For this reason, different systems of cooling are used, and more recently, a new system based on compressed air (Boswell, 2008) or cryogenic cooling (Natasha et al., 2016). Moreover, these procedures are considered as environmental-friendly. Although in the machining processes the cutting forces are lower in dry (Alvarez et al., 2011), and achieve lower forces dependent of type of tool used Domingo et al. (2015), the cooling could contribute to reduce them, under particular conditions.

On the other hand, the polymer composites, also each day more used due to their mechanical and thermal proprieties are similar to other heavier materials. Different types of these composites are being studying regard machining operations; Kuruc et al. (2017) studied techniques based on ultrasonic to reduce the delamination, one of the main problems during the machining of these materials; due to its importance the delamination is a recurrent factor of study (Domingo et al., 2013b). Cavusoglu et al., (2016) analysed the delamination factor and surface roughness after the drilling in GFRP with 50\% and 60\% fibre percentage, finding that the delamination is higher and the roughness is lower in GFRP with 50\% respect to GFRP with 60\%. Domingo et al. (2013b) found that a reinforcement of $30 \%$ of glass fibre in the Poly-Ether-EtherKetone (PEEK) provokes dissimilar values of thrust forces, torques, delamination, roughness in the drilling, according to cutting conditions. In this context, an interesting material is PA66-GF30, which is utilised in many industries, as automotive, aerospace, among others. In these industrial plants, drilling and tapping operations are performed in this polyamide, as previous operations in the assembly of plates.

Campos-Rubio et al. (2013) studied the behaviour of this material during the drilling, finding that the quality of the holes is dependent on the cutting conditions. Although Domingo et al. (2017) and Domingo et al. (2018) have analysed the tapping operations in polyamides PA66 including the effect of cooling air, the first work is focussed on the thrust forces and in the second work the tap used are dissimilar. In this case, the tap is different from a geometric perspective; this geometry influences on the process variables more than the coating (Armarego \& Chen, 2002), and for this reason the particular taper angle is very important.

As is seen, the machining processes are very complex and many factors affect to the results of the variables. Some of these factors are the type of tool and cutting conditions, mainly, and in this paper, the environmental temperature has been incorporate to analyse its influence on the torque, variable that contribute to control the process.

Therefore, the objectives of this paper are the following: i) Determine the torque during the tapping of PA66-GF30 with a tap of $15^{\circ}$ as taper angle, and ii) Find the conditions of temperature and cutting speed that allows reducing the torque with a tap of $15^{\circ}$ as taper angle. 


\section{Methodology}

This section are devoted to experimental and statistical methodology, with explanations of methods, equipment, tools and software used during the planning, execution and analysis of this research.

\subsection{Experimental Procedure}

An experimental methodology was used during this research. Plates of PA66-GF30 of thickness of $6.5 \mathrm{~mm}$ were tapping. The main physical, mechanical and thermal proprieties of this material can be seen in Table 1. The cutting speeds used are 15, 37.5 and $60 \mathrm{~m} / \mathrm{min}$ and at environmental temperatures of $-18,2$ and $22{ }^{\circ} \mathrm{C}$. The latter is the room temperature and -18 and $2{ }^{\circ} \mathrm{C}$ are achieved with a vortex tube that provides compressed cooling air. During the process, the monitoring allowed determining the torque through a piezoelectric dynamometer and a multichannel amplifier, both Kistler, models $9257 \mathrm{~B}$ and 5070A respectively. These data were processed by means of DasyLab software.

\begin{tabular}{|l|l|}
\hline Propriety & Value \\
\hline Density & $1350 \mathrm{~kg} / \mathrm{m}^{3}$ \\
\hline Tensile strength & $93.1 \mathrm{MPa}$ \\
\hline Elongation at break (dry) & $3.5 \%$ \\
\hline Elongation at break (wet) & $5 \%$ \\
\hline Brinell hardness (dry) & $270 \mathrm{MPa}$ \\
\hline Maximum service temperature, air (short term) & $200^{\circ} \mathrm{C}$ \\
\hline Maximum service temperature, air (long term) & $110^{\circ} \mathrm{C}$ \\
\hline Deflection temperature & $250{ }^{\circ} \mathrm{C}$ \\
\hline Melting temperature & $260{ }^{\circ} \mathrm{C}$ \\
\hline Coefficient of thermal expansion, linear & $36 \mu \mathrm{m} / \mathrm{m}^{\circ} \mathrm{C}$ \\
\hline Water Absorption & $5.5 \%$ \\
\hline Moisture Absorption & $1.5 \%$ \\
\hline
\end{tabular}

Tab. 1. Main proprieties of PA66-GF30.

Taps M12×1.75 mm were used in these tests. The features of the taps are described in Table 2, where the geometric and material composition are given. In Fig. 1 can be seen the tap (a), its profile (b) and the effect of cooling air in the tap (c).

\begin{tabular}{|l|l|}
\hline Tool material & HSS-E \\
\hline Coating & TiN \\
\hline Number of flutes & 4 \\
\hline Chamfer form & B \\
\hline Class of fit & $6 \mathrm{H}$ \\
\hline Taper angle & $15^{\circ}$ \\
\hline
\end{tabular}

Tab. 2. Features of the tap. 
Domingo, R.; De Agustina, B. \& Marin, M. M.: Effect of Cooling on the Torque of ...

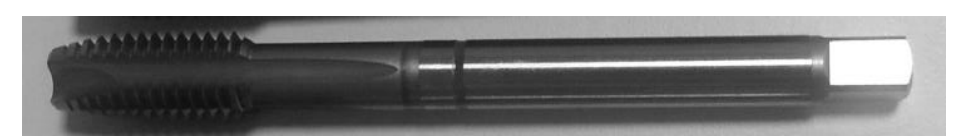

(a)

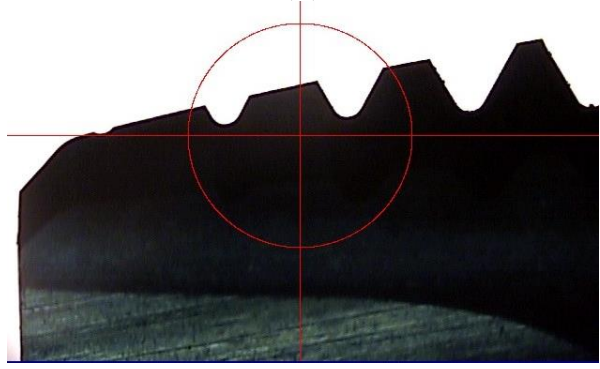

(b)

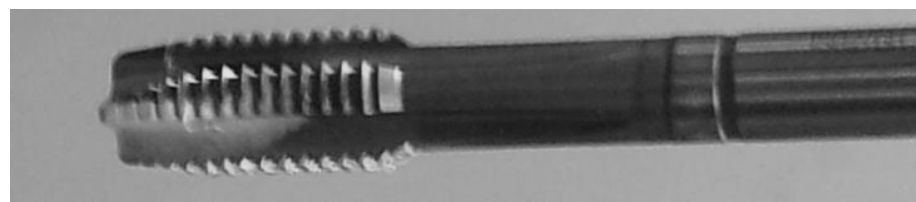

(c)

Fig. 1. Tap, a) tap coated of TiN, b) profile, c) incidence of cooling air in the tap.

\subsection{Statistical Procedure}

The experimental results obtained were statistically processed. A design of experiments based on response surface was realised, with two factors (temperature and cutting speed) and three levels $\left(-18,2\right.$ and $22^{\circ} \mathrm{C}$ for the temperature factor and $15,37.5$ and $60 \mathrm{~m} / \mathrm{min}$ for the cutting speed factor) to develop a second-order regression model. The equation (1) shows the expression of response surface of second-order.

$$
\mathrm{Y}=\beta_{0}+\sum_{i=1}^{k} \beta_{i} X_{i}+\sum_{i=1}^{k} \beta_{i i} X_{i}^{2}+\sum_{i} \sum_{m} \beta_{i m} X_{i} X_{m}+\varepsilon
$$

Where $Y$ is the response to be predicted, $\beta$ is the coefficient of regression, $X$ is the main effect parameter, $X_{i} X_{m}$ is the interaction between parameters and $\varepsilon$ is the error.

Later an analysis of variance (ANOVA) was conducted for these results to find significant main factor or interactions at a confidence level of 95\% (Montgomery, 2012). The regression models based on the response surface can provide a good fit for variables in manufacturing environments (Simunovic et al., 2013) and it is an optimisation technique identified by Kumar (2017); in order to know the precision of the fit, the coefficients $R^{2}$ (coefficient of determination) and $R^{2}$-adj (adjusted coefficient of determination) are calculated. Higher values of theses coefficients indicate an acceptable fit (Montgomery, 2012). The software used in these data statistical analysis was Statgraphics.

\section{Results}

This section shows the results obtained during the research. For these reasons, it has been structured in three subsections devoted to experimental results, the analysis of variance and the development of fitted model. 


\subsection{Experimental Results}

Table 3 shows the results obtained in the experimental tests according to different cutting speeds and under different temperatures. A clear influence of these parameters can be appreciated in these values.

\begin{tabular}{|l|l|l|l|}
\hline Test & Temperature $\left[{ }^{\circ} \mathrm{C}\right]$ & Cutting speed $[\mathrm{m} / \mathrm{min}]$ & Torque $[\mathrm{N} \cdot \mathrm{m}]$ \\
\hline 1 & -18 & 15 & 1.5 \\
\hline 2 & 2 & 15 & 0.9 \\
\hline 3 & 22 & 15 & 1.7 \\
\hline 4 & -18 & 37.5 & 1.8 \\
\hline 5 & 2 & 37.5 & 0.6 \\
\hline 6 & 22 & 37.5 & 1.5 \\
\hline 7 & -18 & 60 & 1.5 \\
\hline 8 & 2 & 60 & 0.4 \\
\hline 9 & 22 & 60 & 1.4 \\
\hline
\end{tabular}

Tab. 3. Experimental values of torques.

\subsection{Analysis of Variance}

Table 4 shows the results from ANOVA. In it can be observed, as there only is a significant factor, $\mathrm{A}^{2}$ because its p-value is less than 0.05 (Kutner et al., 2005). This effect of the temperature is very high and it achieves a percentage of $88.28 \%$. In Fig. 2 can be seen this effect, as standardized effect, on the torque and its difference respect to the others.

\begin{tabular}{|l|l|l|l|l|l|}
\hline Source & $\begin{array}{l}\text { Sum of } \\
\text { squares }\end{array}$ & Df & Mean square & F-ratio & P-value \\
\hline A: Temperature & 0.0104167 & 1 & 0.0104167 & 0.38 & 0.5810 \\
\hline B: Cutting speed & 0.120417 & 1 & 0.120417 & 4.40 & 0.1269 \\
\hline AA & 1.77347 & 1 & 1.77347 & 64.76 & 0.0040 \\
\hline AB & 0.015625 & 1 & 0.015625 & 0.57 & 0.5049 \\
\hline BB & 0.00680556 & 1 & 0.00680556 & 0.25 & 0.6524 \\
\hline Total error & 0.0821528 & 3 & 0.0273843 & & \\
\hline Total (adj.) & 2.00889 & 8 & & & \\
\hline
\end{tabular}

Tab. 4. ANOVA results.

\subsection{Fitted Model}

The values obtained of $R^{2}$ and $R^{2}$-adj are $95.91 \%$ and $89.09 \%$ respectively. These values allow affirming that the variability of the torque is explained in a $95.91 \%$ and that the model -described in the equation (2)- is suitable in almost a $90 \%$ to compare models with different number of independent variables.

$$
\mathrm{T}=0.75-0.006 \times \mathrm{A}+0.002 \times \mathrm{B}+0.002 \times \mathrm{A}^{2}-0.0001 \times \mathrm{AB}-0.0001 \times \mathrm{B}^{2}
$$


Domingo, R.; De Agustina, B. \& Marin, M. M.: Effect of Cooling on the Torque of ...

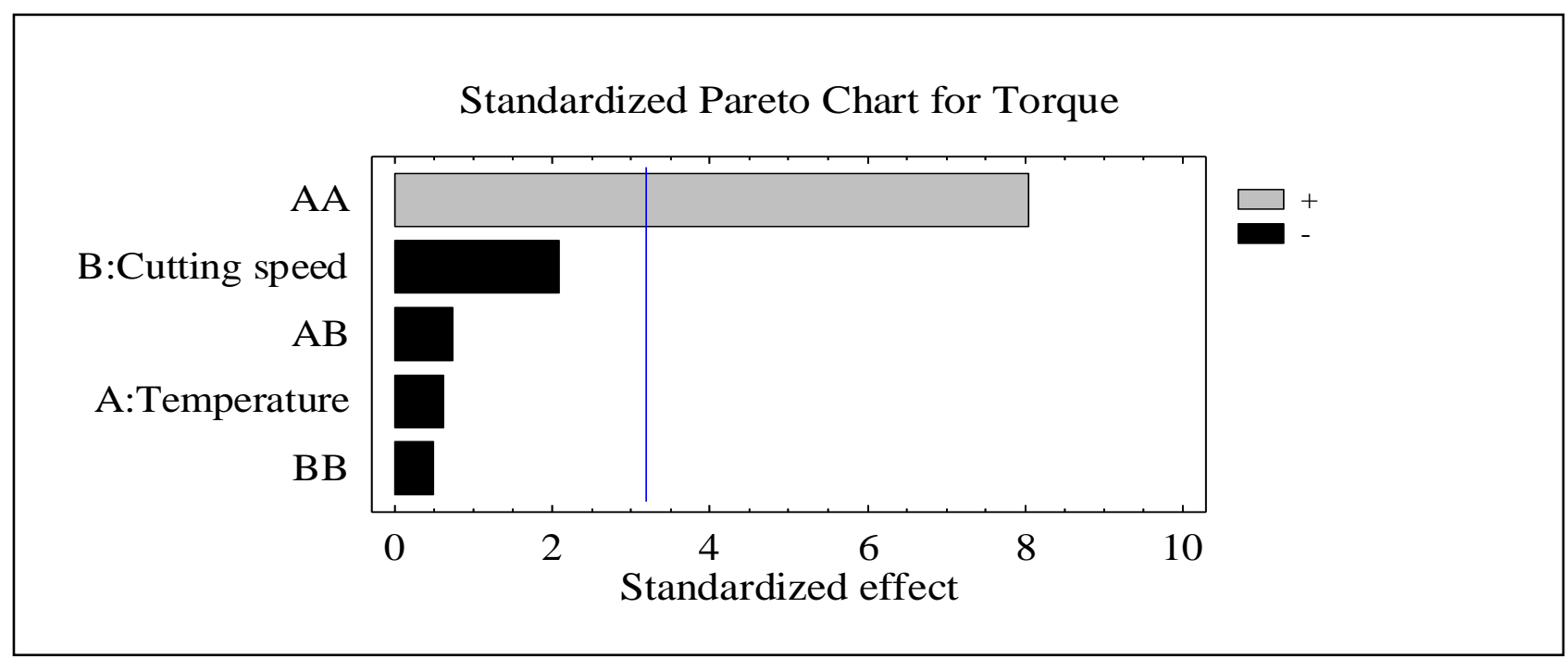

Fig. 2. Pareto Chart for standardised effect.

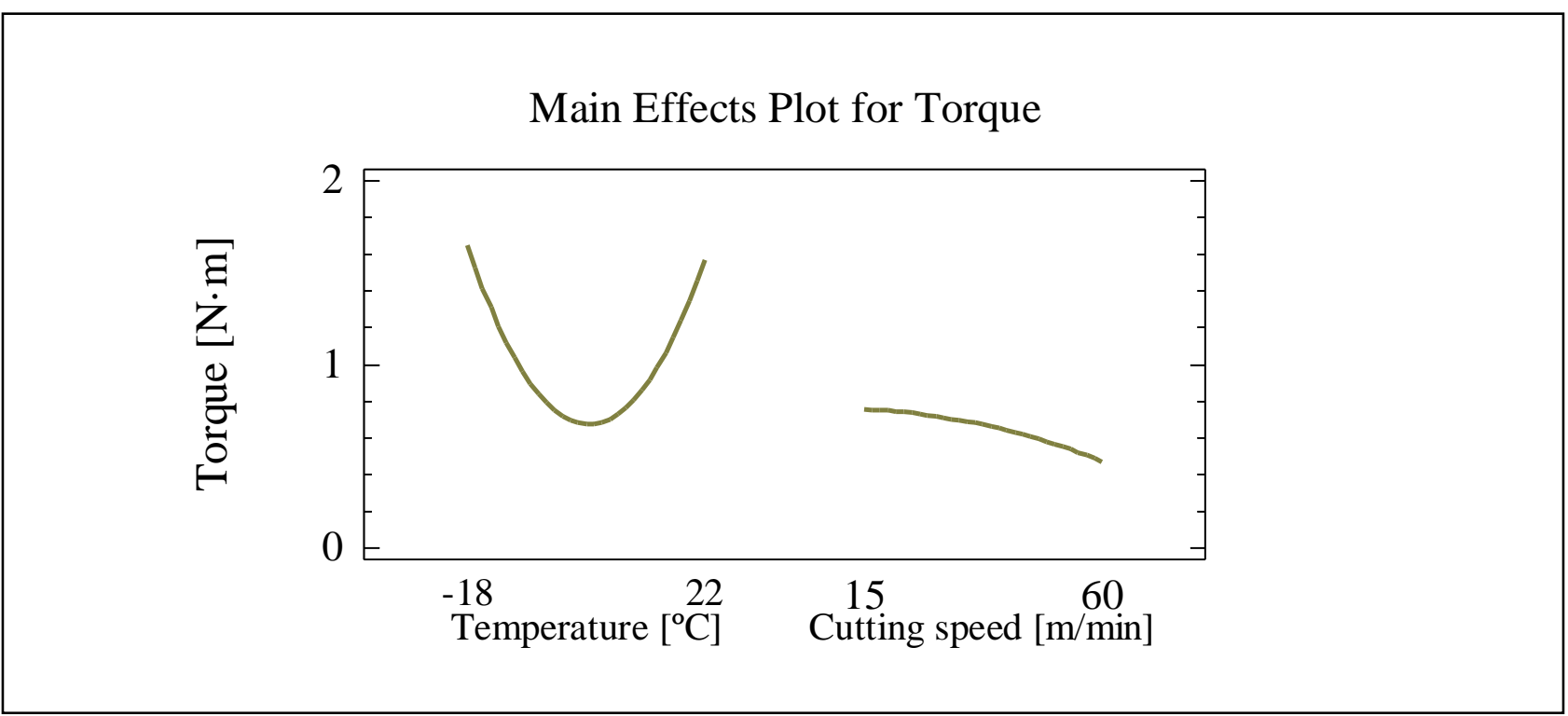

Fig. 3. Values of torque according to fitted model.

Estimated Response Surface

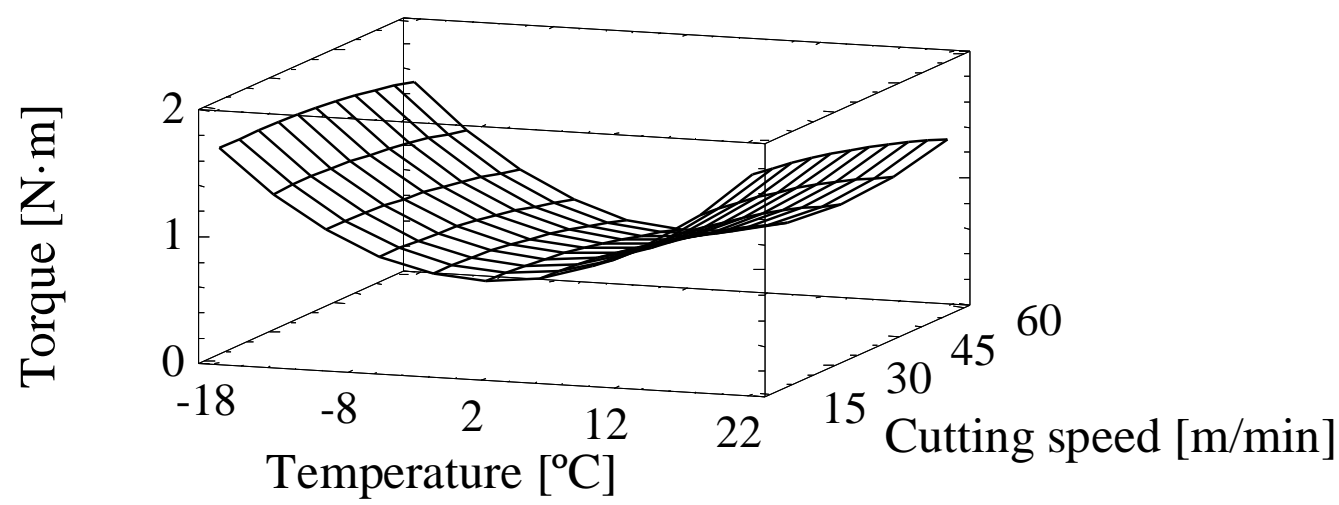

Fig. 4. Estimated response surface for torque. 
The application of the fitted model, described in equation (1), to values can be observed in Fig. 3, which shows clearly that the lowest values of torques are given at temperatures close to $0{ }^{\circ} \mathrm{C}$ and at high cutting speed $(60 \mathrm{~m} / \mathrm{min})$, within of studied range. In Fig. 4, the estimated response surface can be seen; it gives a more detailed perspective, and in it can identified the optimum point found to apply the fitted model; the minimum torque can be achieved at $3{ }^{\circ} \mathrm{C}$ and $60 \mathrm{~m} / \mathrm{min}$. Therefore, the cooling helps reduce the values of torques. This is positive because the torque is responsible for most of the generated energy during the tapping process. However, a strong cooling would not be recommended. Moreover, note that the cutting speed, non-significant factor according to ANOVA results, has a very low incidence on the outcomes.

\section{Conclusion}

The tapping process has been analysed; threaded holes have been executed in plates of PA66-GF30 with a tap of $15^{\circ}$ as taper angle and TiN as coating. These tests have been carried out under different environmental temperatures by means of compressed cooling air. The range used are focussed on cutting speeds of $15,37.5$ and $60 \mathrm{~m} / \mathrm{min}$ and environmental temperatures of $-18,2$ and $22^{\circ} \mathrm{C}$, achieved by vortex tube. After an experimental and statistical analysis, the lower torque can be found at temperatures close to $3{ }^{\circ} \mathrm{C}$ and at high cutting speeds in the range studied, although the significant factor is the temperature; the cutting speed has a low influence.

It is convenient to considerer that the range of cutting conditions and the type of tap limited the conclusions. As future research, the authors will try to extend these features and to increase the number of variables to study.

\section{Acknowledgements}

The authors thank the Spanish Ministry of Economy, Industry and Competitiveness for funding received through the DPI2014-58007-R project, and the College of Industrial Engineers of UNED for its support through the 2018-ICF09 project.

\section{References}

Alvarez, R.; Domingo, R. \& Sebastian, M.A. (2011). The formation of saw toothed chip in a titanium alloy: Influence of constitutive models. Strojniški Vestnik - Journal of Mechanical Engineering, Vol. 57, pp. 739-749, ISSN 0039-2480.

Armarego, E.J.A. \& Chen, M.N.P. (2002). Predictive cutting models for the forces and torque in machine tapping with straight flute taps. CIRP Annals - Manufacturing Technology, Vol. 51, pp. 75-78, ISSN 0007-8506.

Boswell, B. (2008). Use of air cooling and its effectiveness in dry machining processes. Ph.D. Thesis, Department of Mechanical Engineering, Curtin University of Technology, Bentley, Perth, Australia.

Campos-Rubio, J.C.; da Silva, L.J.; de Oliveira-Leite, W.; Hallak-Panzera, T.; RibeiroFilho, S.L.M. \& Davim, J.P. (2013). Investigations on the drilling process of 
unreinforced and reinforced polyamides using Taguchi method. Composites Part B: Engineering, Vol. 55, pp. 338-344, ISSN 1359-8368.

Cavusoglu, I.; Walcher, E.M.; Ugur Tuncer, G. \& Durakbasa, N. (2016). Effects of the fiber percentage rate of the GFPR composites, Chapter 30 in DAAAM International Scientific Book 2016, pp. 335-342, B. Katalinic (Ed.), Published by DAAAM International, ISBN 978-3-902734-09-9, ISSN 1726-9687, Vienna, Austria.

Domingo, R.; Calvo, R.; Marín, M.M. \& de Agustina, B. (2017). Influence of tool cooling on thrust forces in tapping operations of reinforced polyamide. Procedia Manufacturing, Vol. 13, pp. 343-347, ISSN 2351-9789.

Domingo, R.; de Agustina, B. \& Marín, M.M. (2018). A multi-response optimization of thrust forces, torques, and the power of tapping operations by cooling air in reinforced and unreinforced polyamide PA66. Sustainability, Vol. 10, No. 3, 889, ISSN 2071-1050.

Domingo, R.; García, M. \& Gómez, M.R. (2013a). Determination of energy during the dry drilling of PEEK GF30 considering the effect of torque. Procedia Engineering, Vol. 63, pp. 687-693, ISSN 1877-7058.

Domingo, R.; García, M.; Sánchez, A. \& Gómez, R. (2013b). A sustainable evaluation of drilling parameters for PEEK-GF30. Materials, Vol. 6, pp. 5907-5922, ISSN 19961944.

Domingo, R.; Marín, M.M.; Claver, J. \& Calvo, R. (2015). Selection of cutting inserts in dry machining for reducing energy consumption and $\mathrm{CO} 2$ emissions. Energies, Vol. 18, pp. 13081-13095, ISSN 1996-1073.

Kumar, S. (2017). Review on optimization techniques used for determining machining conditions to get effective tool life and surface finish, Chapter 19 in DAAAM International Scientific Book 2017, pp. 235-264, B. Katalinic (Ed.), Published by DAAAM International, ISBN 978-3-902734-12-9, ISSN 1726-9687, Vienna, Austria. Kuruc, M.; Vopat, T.; Simna, V. \& Necpal, M. (2017). Influence of ultrasonic assistance on delamination during machining of different composite materials, Proceedings of the 28th DAAAM International Symposium, pp. 0392-0399, B. Katalinic (Ed.), Published by DAAAM International, ISBN 978-3-902734-11-2, ISSN 1726-9679, Vienna, Austria.

Kutner, M.H.; Natchtsheim, C.J.; Neter, J. \& Li, W. (2005). Applied linear statistical models, 5th ed., McGraw-Hill Irwin, ISBN 978-0073108742, New York, NY, USA.

Montgomery, D.C. (2012). Design and analysis of experiments, 8th ed., John Wiley \& Sons Inc., ISBN 978-1118146927, New York, NY, USA.

Natasha, A.R.; Ghani, J.A.; Che Haron, C.H.; Syarif, J. \& Musfirah, A.H. (2016). Temperature at the tool-chip interface in cryogenic and dry turning of AISI 4340 using carbide tool. International Journal of Simulation Modelling, Vol. 15, No. 2, pp. 201212, ISSN 1726-4529.

Simunovic, G.; Simunovic, K. \& Saric, T. (2013). Modelling and simulation of surface roughness in face milling. International Journal of Simulation Modelling, Vol. 12, No. 3, pp. 141-153, ISSN 1726-4529. 